\title{
University-Community Engagement: A grid-group analysis
}

DAVID LOW

\author{
The value of the idea of freedom arises \\ only to oppose the idea of necessity. \\ (Kevelson 1993, p. 1)
}

U

niversity-community engagement is increasingly becoming a

key focus of Australian universities (see, for example, Australian Universities Community Engagement Alliance 2005; Funding

Australian Universities for Community Engagement 2005; Winter et al. 2006; and Innovative Research Universities Australia 2006). There is little agreement, however, as to the values underlying the term 'community engagement', or the kind of activities it ought to represent. For example, university-community engagement might be thought of as a vehicle for teaching and learning, research,

developing industry and professional links, marketing the university, or perhaps enhancing civic altruism. All of these kinds of activities 
can be described by the term university-community engagement, and in an Australian context it is all of these things. It would seem that there are a vast number of stakeholders that have become active collaborators in the work of Australian universities for an equally diverse number of reasons (Commonwealth of Australia 2002).

In this social context, researchers at universities can no longer assume that their findings can be thought of as 'authorised truth' and simplistically expect the public and its social institutions to accept and incorporate the findings of university research programs 'on trust' (McGee \& Lyne 1987). Given the identified trend toward engagement and collaboration, I propose that we view the work of university-community engagement as being itself a process of enquiry rather than a collection of problematically dissociated university functions. In this view, university-community engagement is transformed into a system that must continue to be responsive to the dissent of its constituency, or it does not exist (Low 2003).

I define dissent as a feeling or way of thinking that opposes an accepted viewpoint, and enquiry as a method of communication that aims to find out the truth. My argument is that by viewing university-community engagement as a process of enquiry that is reliant on dissent, we can simultaneously allow two possibilities: enquiry can function to keep communication closed to the wider community (through its self-referential autonomy), and connected to the community (through its communicational commitment to engaging with dissent).

The above dialogical view of university-community engagement also suggests that the purpose of enquiry as a whole is something internal or immanent to any social system. In this sense, we do not 'transfer' or 'transmit' knowledge between social systems, but, rather, we engage a method that enables the recognition of a shared object of enquiry - its entelechy (Nicholls 2000). Thus, a university's ability to stabilise itself in the face of both internal and external challenges is founded upon its ability to recognise its own inherent instability and continually adjust itself (to learn and grow) in response to this dissent (see, for example, Luhmann 1990; and Michael Thompson 1992). Universities, therefore, must continually enquire into, and regulate their responses to, the surprises dissent embodies if they are to survive. In short, the self-reflexive operation of dynamic social systems (such as universities) requires that communication as enquiry continue interminably. 
How does a university regulate itself to ensure that communication as enquiry continues indefinitely, and how does this mode of regulation affect the manner in which universities engage with external stakeholders? To answer these questions, we will need to examine universities as systems controlled by a system of differentiated communication. Following the lead of Kecskes (2006), the theory I shall use to guide us in this task is derived from the work of anthropologist Mary Douglas.

\section{GRID-GROUP THEORY}

Mary Douglas is well known for her grid-group technique used for analysing the dynamics of social systems (see, for example, Douglas 1973, 1982a, 1982b, 1989, 2001; Douglas \& Wildavsky 1982; Douglas \& Calvez 1990; Mamadouh 1999; and Spickard 1989). Douglas' method is to superimpose two dimensions of social commitment as indicated in the diagram below. The term 'grid' is used to represent the degree of individuation: 'The term grid suggests the cross-hatch of rules to which individuals are subject in the course of their interaction' (Douglas 1982a, p. 192). Thus, at the top of the diagram is strong grid, a place where there are visible rules of control (that is, a high degree of social regulation and classification), while at the lower end, weak grid, is a place where 'formal classifications fade, and finally vanish' (Douglas 1982a, p. 191).

On the other axis, the term 'group' is used to represent a dimension of social incorporation: 'The group itself is defined in terms of the claims it makes over its constituent members, the boundary it draws around them, the rights it confers on them to use its name and other protections, and the levies and constraints it applies' (Douglas 1982a, p. 192). Thus, to the left-hand side of the diagram is weak group (weak social incorporation) and to the right strong group (strong social incorporation). These twin dimensions are used to yield a four-fold model of social organisation.

Much of Douglas' use of the model was directed at explaining the styles of thinking and behaving characteristic of each of the four quadrants, which Douglas called 'cultures'. The quadrants (A, B, C, and D) and their mnemonic titles (individualism, isolates, hierarchy, and enclaves) provide four distinctive contexts within which a 'cultural bias' is generated. The cultural bias of each quadrant is maintained through the explanations and justifications that seem 


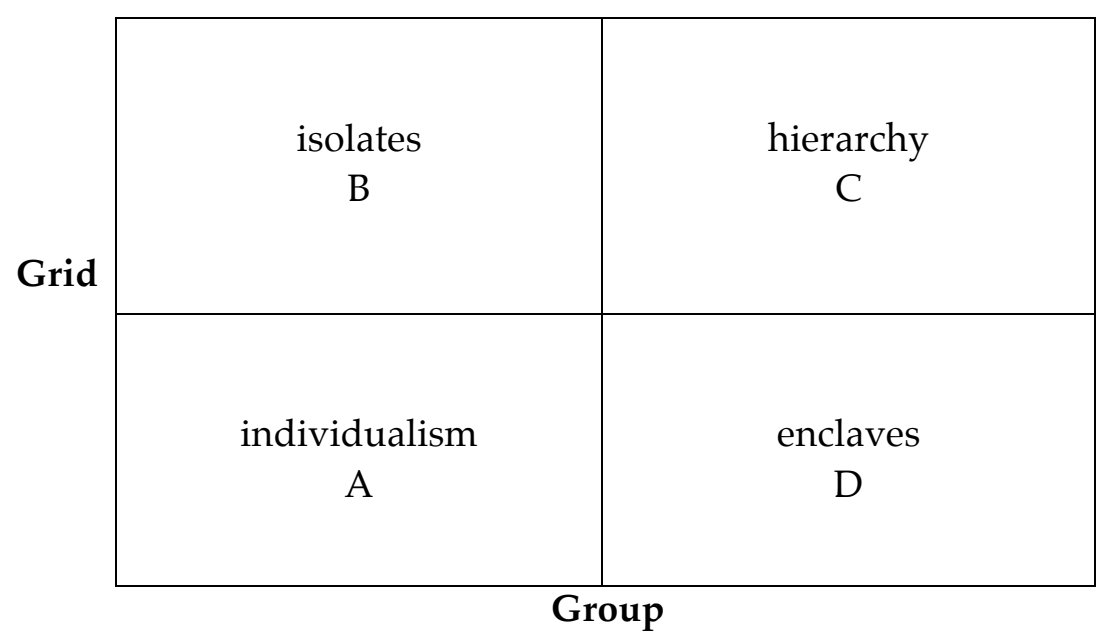

Douglas' four types of social environment (adapted from Douglas 1982b, p. 11).

plausible to people communicating in each quadrant. Thus, for Douglas, each quadrant represents a culture within which certain attitudes and behaviours are characteristic:

Square A (low grid, low group) allows options for negotiating contracts or choosing allies and in consequence it also allows for individual mobility up and down whatever the current scale of prestige and influence. Square B (high grid, low group) is the environment which ascribes closely the way an individual may behave. In any complex society some categories of people are going to find themselves relegated here to do as they are told, without the protection and privileges of group membership. Square $C$ is the environment of large institutions where loyalty is rewarded and hierarchy respected: an individual knows his place in a world that is securely bounded and stratified. Finally, square D is defined by the terms of the analysis as a form of society in which only the external group boundary is clear: by definition all other statuses are ambiguous and open to negotiation. (Adapted from Douglas 1982b, p. 4)

In the present context, we are interested to discover the communicational characteristics of the quadrants and their possible 
relationship to the concerns of university-community engagement practitioners and/or researchers. We are also interested to find out how dissent functions in each of the quadrants. As noted earlier, dissent is a vital communication factor enabling university research communities to constitute and maintain themselves through enquiry. Both dissent and enquiry are vital to the creation of new knowledge, the task of universities. Thus, without a method to nurture and reveal dissent, universities would be unable to even recognise different ways of being in the world, and enquiry would be rendered impossible (Hawes 1999, p. 235).

To examine what happens to dissent in different social or cultural contexts, we shall think about what it would be like to be communicating about a specific university-community engagement issue under the communicational constraints of the grid-group dimensions. What we imagine could be any issue at all - the only proviso here is that the issue involves the mobilisation, or the possibility of, a dissenting view. This imagining method will allow us to discuss how university-community engagement is coordinated in different ways via different methods of social organisation (that is, via communication). In other words, the grid-group method of analysis will enable us to see what it would be like to communicate about a specific issue within four distinct 'communicational communities' (Ransdell 1998). Thus, for our present purpose, the grid-group model allows us, as Douglas put it, 'to understand the relation between the inside structure of an organization and the insides of its members' heads' (Douglas 1989, p. 172). More specifically still, we can use the grid-group model to identify different methods of university-community engagement, and then examine the different ways in which universities might respond to dissent, the communicational welding agent for enquiry.

\section{A SEMIOTIC EPISTEME FOR GRID-GROUP ANALYSIS}

Douglas argues that we are 'unable to conceive of the individual's environment if it is not a group of some kind' (Douglas 1982a, p. 192). In other words, it is impossible to conceive of an individual without also thinking about how that individual communicates within a group, or with other groups. An individual's judgement in regard to a specific issue is consequently constructed from within an evolving social dialogue with other groups (see, for example, 
Perelman 1982; and Corrington 1994). This much we can agree on. What is perhaps missing from Douglas' conception of 'environment', however, are influences derived from sources that are 'other' than the social system itself, that is, from sources the existence of which is not attributable to what we want or do not want to be the case. These sources, I argue in contrast to Douglas, have a being of their own that is independent of what we think about them, for example, ecosystems, animals, rocks, plants, or at the most generalised level, universes. In my view, a 'de-anthropologised' epistemology is required if we are to also recognise and become responsive to scientific methodologies within the context of a grid-group analysis (Luhmann 1989, p. 78). Indeed, without a theory capable of encompassing scientific communication methods, much of the work of a modern university would remain un-analysable.

This article therefore puts forward the case for a semiotic epistemology in grid-group analysis. I have derived this insight from the work of Charles S. Peirce (1839-1914). In Peirce's view, communication mediates between an independent reality and our reasoning about it (Low 2003). To demonstrate how such an approach might operate in the context of grid-group analysis, I am next going to locate four different methods of communication in Douglas' grid-group diagram. I will then investigate how each of the four communication methods I identify function as an enquiry system for university-community engagement.

In his famous paper The Fixation of Belief, Peirce identifies and discusses four methods we can use to obtain a settled state of belief (Peirce 1955, p. 10ff). In the following diagram, I have renamed each quadrant with one of Peirce's four methods of enquiry: the method of tenacity; the method of authority; the a priori method; and the method of science. Each method differs from the other three in regard to the communicational characteristics used to persuade the participants to reach agreement. Put another way, each method solves the problem of dissent in relation to university-community engagement in a different manner.

In an ideal world, we have the freedom to choose between these methods. Under the constraining influence of the grid-group dimensions, however, our choices are restricted by the communicational bias of the quadrant we are communicating within, or at least, that is the proposition I am investigating in this article via Douglas' grid-group constructs. 


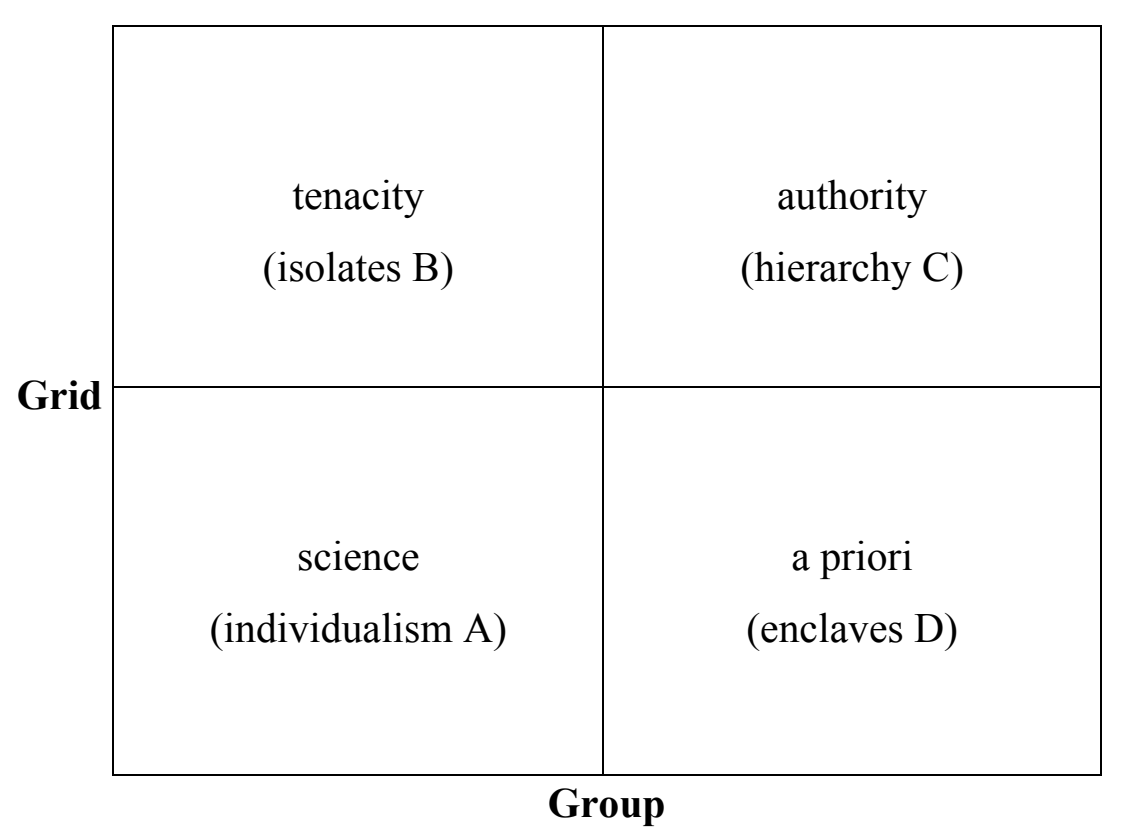

A Peircean grid-group communicational community diagram.

\section{TENACITY (IsOlATES B)}

According to Peirce, the method of tenacity operates to maintain existing beliefs through avoiding contact with any contradictory evidence. People in this quadrant therefore protect themselves from doubt by avoiding situations or information that might give rise to doubt in the first place. If this is not possible, the individual tenaciously clings to a former belief to ward off doubt. In this sense, the method of tenacity operates to protect the individual from group pressures (hence, weak group), while maintaining a sense of powerlessness in relation to the forces of social regulation (hence, strong grid). Dissent in this quadrant is equivalent to personal disintegration. To ward off this, the individual regresses to an existing belief, or an existing rule for action. Holding to this view tenaciously will solve the immediate problem at hand. Peirce compares the method of tenacity to that of an ostrich burying its head in the sand (Peirce 1955, p. 11). Whether it was a good idea to do so can only be determined retrospectively. 


\section{AUTHORITY (HIERARCHY C)}

The method of authority is also based on the recognition of dissent, but here we move toward the strong end of the group dimension, thus dissent cannot be repressed by the first method (tenacity) as effectively. To remain incorporated within the group, if that is the intention, the individual, or perhaps a sub-group, must resolve the conflict made evident by dissent by submitting the issue to authority, for example, to an authorised decision-making process, or perhaps an authorised 'expert' or 'judge'. This method, therefore, involves a selfidentification with the pre-authorised beliefs of the group in respect to any specific problem and the correct method to solve problems. In other words, membership involves a voluntary submission to the processes of social regulation, which is why I have located this method of fixing belief at the strong end of the grid dimension. Often the key issue in this quadrant is whether there is sufficient time or resources available to resolve the conflict. If not, a decision will be imposed.

\section{A Priori (EnClaves D)}

The a priori method operates to eradicate dissent through reason, but without recourse to experiential evidence. Peirce characterises this approach to the fixation of belief as the 'philosophical' method. He suggests that what we find reasonable via this method is a matter of intellectual 'taste' or 'fashion'. In this quadrant, then, whatever an individual believes must remain consistent with the opinion of a group. It is a group consensus that determines what is to be believed, which is why I locate this method at the strong end of the group dimension. If a cohesive group's interpretation of new information remains consistent with what is already believed, the information is usually found compelling on this basis alone. The third method, therefore, resolves dissent through an appeal to the binding power of ideas rather than by a submission to authority. Consequently, the intellectual freedom of this communicational community cannot be closely regulated without reducing it to either of the previous methods (tenacity or authority), which is why I locate the a priori method at the weak end of the grid dimension.

\section{SCIENCE (INDIVIDUALISM A)}

The method of science operates to eradicate doubt by subjecting hypothesised resolutions to dissent to experimentation and 
observation. I am going to cover the characteristics of this quadrant in a little more detail, as how this method goes about resolving disputes is key to understanding the role of enquiry in universities.

As argued earlier, enquiry-based communicational communities form around a common concern for a subject matter that is independent of what we want to be the case rather than a special ideological or philosophical preference. Thus, as I have noted elsewhere (Low 2000), enquirers who consider group conformity to be more important than finding out what is really the case cannot be said to be communicating scientifically. Cooperation in a scientific communicational community has as its object the investigation of the truth of its subject matter, not the construction of a truth the communicational community wants to be true.

The method of science, therefore, involves factors identified and made operational by the other three methods of fixing belief, but brings into play one vital extra factor. In the method of science, the being of the object of enquiry plays the determining role in the fixation of belief. For example, I might say to someone, 'It's very smoggy today'. The person I say this to might respond by saying, 'How do you know that?' I could then respond by saying, 'Go outside and look at the colour of the sky and smell the air. If you do this, you will find that the sky looks brown and the air smells like burnt petrol'. If the person I have addressed this claim to does this, they will likely be compelled to the same conclusion I have asserted via a mediated experiential contact with the subject matter of my assertion. In this sense, my communication is meaningful if, and only if, my interlocutor responds to my communication appropriately that is, in a manner that will reveal the object of my assertion. If this is done, and there remains some disagreement about what is to be accepted as the object of my claim (for example, 'That's not smog, that's progress!') this can only be resolved by dialogic enquiry with the same object in mind. In this sense, the relational consequences of the object of enquiry can only be found out by enquiry. We cannot impose our meanings on the object by stipulating that it must be as we command or think it to be (the position of the other three quadrants). The object of enquiry is free to object to what we say about it in the method of science (Latour 2000).

Even the most complex scientific enquiries follow the basic method described above. For our present purpose, then, note that an 
assertion (that is the conditional proposition asserted to be true) made in the science quadrant is made to an audience considered distributively rather than collectively. In a scientific community, the scientist addresses 'whomever the assertion may concern' (Ransdell 1998). As such, the audience is not a collection of people who must, as a group, accept or reject the claim according to whether it coheres with an existing system of beliefs (that which we call 'knowledge'). This is why I locate the method of science at the weak end of group.

Note also that there can never be some kind of mechanical procedure that, if adhered to, will guarantee that a claim made in the science quadrant is necessarily true (for example, the object of an assertion might have changed in some important respect that was not anticipated, or the asserter might be mistaken about something). This is why I noted earlier that the truth of any claim in science is ultimately determined by the subject matter or object of enquiry. No amount of social regulation can in itself guarantee that any given claim approximates the truth, which is also why I locate the method of science at the weak end of the grid dimension.

In the science quadrant, then, individuals are (ideally) free to communicate openly and honestly in relation to a specified subject matter of concern. Consequently, there is both less influence and control from others (that is, the group dimension), and individuals are relatively free from social regulation (the grid dimension). In other words, the method of science is dominated by strongly competitive conditions and images of individual autonomy.

I seem to hear my reader ask, 'But surely the method of science is a highly regulated social activity and therefore it should be located in the hierarchy quadrant?' I defend my choice for locating the method of science in the weak grid, weak group quadrant on two further grounds: first, I agree that science is a social activity. As just noted above, when a scientist makes a claim, the scientist does not make it to a communicative community considered as a collective. Rather, the claim is made to anyone who has an interest in determining the truth about the same subject matter (that is, 'to whom it may concern'). This may turn out to be a large number of people, or it may turn out to be a single individual, or perhaps even a person or group of people not yet born. In this sense, there can be no criterion of membership in a scientific communicational community, such as an allegiance to what is already believed (the a priori method), or to that which has been authorised to be believed (the method of authority), or to what 
we habitually believe (the method of tenacity). What is required is an honest and sincere desire to find out. In short, there must be a commitment to the function of truth-seeking in communication.

Second, scientists, in order to be scientists, must be as free as their subject matters. Although the hierarchy quadrant would prefer it if nature could be made to remain fixed in place by decree of its policy or engineered interventions, nature remains something independent of these efforts, as something dynamic and evolving. In this sense, the method of science must also be organic. It cannot be highly regulated or fixed, that is, not without it becoming overly authoritarian, tenacious, or unwilling to admit a new level of information (a priori).

In sum, my modified grid-group diagram is designed to provide an interpretive apparatus within which we can set about describing the communicational characteristics of the methods used to fix belief in each of the quadrants. The proposed method of analysing university-community engagement communication, therefore, follows logically from my earlier argument that communicational communities are constituted by their communication method. Disagreement within a quadrant is thus functionally the same as disagreement with one's self-identified communicational community. In this sense, the method for settling opinions operative in each quadrant constitutes a suitable name for the communicational community of the quadrant.

\section{THE HYPERCYCLE OF UNIVERSITY-COMMUNITY ENGAGEMENT}

The purpose of my modified grid-group diagram is to provide a structured typological space within which four distinct social agorae for university-community engagement can be identified and discussed - both in relation to their internal characteristics, and in relation to each other. As Thompson has noted, each of the methods identified via any grid-group analysis seriously contradicts the other three, yet each is complementary to the regulation of a social system as a whole. As Thompson states, the four quadrants:

... form themselves into a hypercycle. Each way of life, it turns out, does something for the next that it cannot do for itself. (Thompson 2000, p. 191, original emphasis) 
For example, the method of authority would be a suitable method for enforcing the business contracts that arise out of the method of science. In turn, the excesses of the method of authority would provide the a priori method with something to criticise and rally around, and the method of tenacity would give the method of authority someone to categorise and develop policy in respect to. Thus, since each communicational community acts as a source of disagreement or difference, it is necessary to the others in a system of communication: the reproduction of each way of life ensures the survival of the other three.

As suggested earlier, university-community engagement at a generic level is made possible via a method of communication called enquiry, which is also why recognising and nurturing a role of dissent is so vital to university-community engagement. My findings so far suggest, however, that enquiry operates solely in the science quadrant of our modified grid-group diagram. The communicational constraints of social incorporation (grid) and group membership (group) are minimised here, allowing the freedom necessary for enquiry within a universe of discourse that is equally free (this is most often termed 'academic freedom'). In the science quadrant, anything imaginable is possible and any possibility is imaginable (at least in theory). In short, the possibilities for selecting ideas to investigate in this quadrant are derived from interactions with a universe of discourse that is potentially endless in its possibilities.

However, it is also this very characteristic of the method of science that shows us why universities cannot operate in the science quadrant in isolation. There must always be something other than the self-referential autonomy of university research to encourage new directions for enquiry and to correct errors, for example, when theory is put into practice. Put another way, a university must derive disagreement and direction from sources that are external to the university itself. In this view, when the innovations that emerge from the science quadrant find their way to the other three quadrants, they are greeted in different ways according to that quadrant's preferred communication method. This in turn determines whether ideas derived from the science quadrant are capable of being incorporated into a broader social system, and which communication strategies are appropriate to achieving this acceptance (Luhmann 1989, p. 82). As the hypercycle functions by utilising each communication method (that is, each method for fixing belief), each method is necessary. 


\section{IMPLICATIONS FOR COMMUNICATION STRATEGIES}

Each of the communicational commitments I have identified arises out of a distinct method of fixing belief, and each is proposed to be necessary to a university-community engagement communication system. One of the advantages of grid-group analysis, then, is that it enables us to see that there are a number of paths that could be used to engage the system with those matters relevant to the life of universities.

Our diagram also reveals a number of concomitant difficulties due to conflicting communication methods and assumptions. As we have seen, each quadrant has a distinctive method for processing communication, thus we cannot assume that a communication generated in the science quadrant, for example, will be interpreted or discussed in the same way in another communication quadrant. Indeed, the analysis undertaken here would suggest that such an expectation is impossible. The new will always be processed in a different manner in the other quadrants. This is to be expected, as, after all, there is no need to communicate research to an audience when the object of the research is already known and accepted by that audience. In this sense, university-community communication is premised on failure - if it doesn't surprise an audience to some degree, it's not something new that is being communicated.

Perri 6 et al. (2006, pp. 75-76) have analysed the idea of surprises within the context of grid-group theory. Their analysis helps us think about what is likely to occur when communications generated within the science quadrant move to the other three quadrants. Grid-group analysis suggests that if the findings of a university research programme are to be successfully disseminated and taken up in the other quadrants, each of these quadrants should be thought of as a distinct audience with a distinct method of processing messages. Thompson (2000, p. 192), for example, proposes that each quadrant has a distinct 'information handling style' which enables it to accept or reject messages from other quadrants. In respect to universitycommunity engagement communication, Thompson's study and the recent work of Perri 6 et al., as well as our own efforts, suggest that the following considerations may be pertinent to designing better communication strategies for university-community engagement when such communication is generated by the science quadrant. 


\section{TENACITY QUADRANT}

Information from the science quadrant is neither selected nor rejected in any particular way by the method of tenacity. This is due to the social isolation implicit to the quadrant's positioning at the weak end of the group dimension. Autonomy is restricted by social structures and these structures are largely beyond the control of the individual (strong grid), hence the theme of this quadrant is, 'What you don't know can't harm you'. Broadcast media, such as television or radio, are therefore often enlisted to communicate with this quadrant. The idea is to create as many points of attraction as possible so that the new idea can establish itself. However, grid-group analysis would also suggest that messages conveyed by the popular media will fail in this quadrant unless the message is closely matched to existing structures and beliefs. For example, a message designed to motivate recycling would fail unless there were social structures in place to enable recycling. Similarly, a new rule for action may need to be strategically 'reframed' so that the individual can act in accordance with their existing frameworks and communication preferences (Shellenberger \& Nordhaus 2005). For example, medical researchers may increasingly find their work is disseminated to this quadrant through self-help groups on the internet, or via popular television programs such as ER or House (Van Dijck 2003). As these sources are not seen as 'official sources of authorised university-community engagement', individuals in this quadrant do not feel threatened or overwhelmed by them and can select out information that helps them survive.

\section{AUTHORITY QUADRANT}

Information in the authority quadrant is meticulously analysed and classified systematically, preferably via a large bureaucracy with vast information technology resources available to assist in the task. If the information entering this quadrant has not been correctly coded, corrective instructions are sent back to the science quadrant. 'More research' might be commissioned, or alternatively, research that is not deemed useful to the authority quadrant's predetermined categories and priorities is 'axed'. This quadrant would, therefore, have a focus on what is appropriate communication from the science quadrant. Consequently, universities communicating from the science quadrant to this quadrant do so primarily through authorised 
channels such as submissions, hearings and enquiries, for example.

As Douglas and Calvez have argued in regard to an earlier gridgroup analysis (1990, p. 460), communication between the science quadrant and the authority quadrant can be thought of as a 'positive diagonal'. In this sense, there is a functional alliance between the method of authority and the method of science. The authority quadrant commissions research, and the science quadrant carries it out. However, this close alliance is not without its problems. As noted above, the authoritarian quadrant may attempt to 'discipline' the science quadrant, thereby killing off the freedoms of the science quadrant that enable researchers to produce insight. Similarly, the authority quadrant may self-regulate itself into an information gridlock through over-regulation, effectively preventing any new information from entering.

\section{A PRIORI QUADRANT}

The social solidarity of this communicational quadrant is built around exposure to the failings of the other quadrants. As such, conflict sustains this quadrant and information is selected on the basis of whether it conforms to what is already believed to be the case. The uncertain and provisional shades of grey of the science quadrant are therefore quickly transformed into 'black and white' by the a priori quadrant. In other words, doubt is either transformed into knowing, or knowing nothing. Indeed, in order to maintain its absence of structure (weak grid), the a priori method handles new information by subjecting it to a consensus process. In consensus, participants carrying new information can either join in, or refuse to join in. Thus, new information that cannot be incorporated via consensus is labelled 'the enemy'. This would seem to indicate that the content of communication directed at a priori groups should be selected to conform to (or 'partner with') the oppositional purpose of the social solidarity or it will be rejected.

Perri 6 et al. (2006, p. 75) note that universities communicating with this quadrant may encounter the following dynamic. The lack of grid (institutionalisation) makes the support of authority within a priori groups difficult. As such, they will be unable to sustain negotiations with outsiders due to their inability to sustain effective authority internally. Given this, it may be best to approach groups operating under the communication principles of this quadrant only 
if they are at the early stages of their formation. In this case, the information supplied will be used to strengthen common beliefs and maintain a sense of boundary.

When communicating with groups in the latter stages of their development, however, thought might be given to whether the characteristic passionate loyalty and protective impulses of this quadrant will function to reject university-community engagement efforts, no matter how well intentioned. The alternative danger noted above is that any communication will have to be so seriously distorted to be rendered acceptable, that it will no longer be meaningfully linked with its intended object.

\section{WIDER IMPLICATIONS}

The previous discussion is largely premised on the assumption that the science quadrant is where new ideas are most easily generated due to the favourable levels of grid and group. This is perhaps why it is often incorrectly assumed that ideas generated in this quadrant should be the focus of university-community engagement. As noted earlier, however, there are many other reasons a university might want to engage - for example, to recruit new students, to draw in donations, or to teach vocationally. These tasks may be best performed in a different quadrant and therefore the staff involved will adhere to a quite different method of fixing belief.

For example, within the a priori quadrant an idea must appear reasonable or it will be rejected. To seem reasonable, and therefore no longer be open to dispute, ideas in this quadrant are called 'knowledge'. Notions of 'verification' and 'empirical validity' lead to an expectation that everyone should also believe in and accept the knowledge of this quadrant. As such, groups operating in this quadrant believe they can capture and embed knowledge in structures such as field manuals, operational procedures, predictive models or 'best practice' exemplars.

As stressed earlier, applying the above communication forms to the work of the science quadrant will be self-limiting and unproductive. Imposing pre-determined patterns in the science quadrant kills off the very creative process one hopes to facilitate. Seen from the other direction, then, ideas generated in the science quadrant may appear to the a priori quadrant to be either insane or pointless (Kurtz \& Snowden 2003). This is because the ideas of the science quadrant are research ideas and as such are largely useless, at 
least until some later time. It may take decades or even generations for the ideas generated in the science quadrant to be transformed through the hypercycle into 'knowledge' in the a priori quadrant.

The above is why university-community engagement strategies created from the 'knowledge' point of view of the a priori quadrant may not work as expected. For example, the a priori quadrant might use a case study approach to develop a set of guidelines for university-community engagement that it is claimed can be replicated in contexts that have not yet been studied. Applying these a priori guidelines to the science quadrant, for example, would only serve to precipitate confusion, as in the science quadrant patterns are viewed as uncertain and goal-based directives are viewed with scepticism.

Perri 6 et al. has examined some of the self-limiting and unproductive communicational characteristics of the a priori quadrant in detail (2006, p. 75). They argue that since this quadrant structures itself according to asymmetric status and power relations based on role, informal networks that get participants to put aside their formal roles temporarily can be used to create boundary linkages. For example, to create communication linkages with the science quadrant, they recommend that industry leaders and government officials be encouraged to participate in science quadrant activities. This social learning strategy can exploit the formation of bridging networks that unfreeze the institutionalised gridlock so characteristic of the a priori quadrant.

\section{CONCLUSION}

The discussions above indicate ways to think through the strategic implications of university-community engagement communication via grid-group analysis. I have argued that our starting point for the task should always be to view university-community engagement as an enquiry activity. This has led to me suggest that at a social system level, the general purpose of university-community engagement is to find ways of linking the new ideas generated by a university into a broader, more complex social system.

As precautionary corollary to the above, I suggest that we note that an entirely new idea, or what Peirce called a 'detached idea', can never be created by a university. Put another way, the semiotic epistemology for grid-group analysis developed here suggests that 
an entirely new object of research cannot be engaged with (Lyne 1982). The reason for this, according to Peirce, is that the best we can do is fill out and correct already existing ideas (Peirce 1998, p. 327). As Peirce observed:

As to detached ideas, they are of value only so far as, directly or indirectly, they can be made conducive to the development of systems of ideas. There is no such thing as an absolutely detached idea. It would be no idea at all. For an idea is itself a continuous system. But of ideas those are most suggestive which, detached though they seem, are in fact fragments broken from great systems. (Peirce 1976, p. 346)

Thus, we might say that university-community engagement is a task that involves drawing from the experience and existing beliefs of the community, as well as giving to any community an expanded or corrected method for accessing a shared and revised subject matter.

Given the above, university-community engagement might also be said to be a method of communication that welds the dialogic of university-community engagement into a common mind:

This mind may be called the commens. It consists of all that is, and must be, well understood between utterer and interpreter, at the outset, in order that the [communication] in question should fulfil its function. (Peirce 1976, p. 478, original emphasis)

I have stressed that the social system relies heavily on the method of science to draw new information from the universe of the possible into the social commens. Further, I have suggested that it is only in the communicational community known as science that a reality independent of what we think, but not thinking generally, is given epistemological and ontological status. That is, it is only in the science quadrant that the universe can be engaged with dialogically as an equal partner in our enquiry process. In this sense, the science quadrant allows a social system to experience that which is other than itself, and listen and respond to the surprises the other can offer.

The findings of this article therefore suggest that society does not rely on science to guide its actions exclusively. Our grid-group analysis indicates that society uses four distinctly different methods 
of communication to regulate itself. From a systems point of view, then, the method of science serves a Janus-like function in universitycommunity engagement. It presents society with the opportunity to protect itself from threatening new ideas (by suppressing or ignoring the new), as well as the opportunity to incorporate and embrace new ideas (Luhmann 1989, p. 83). This finding also supports a more general thesis: that is, to find a balance between the demands we make of the universe (and the universe's capacity to remain integrated with us) involves recognising that which is other than us as a dialogical collaborator of equal status with society. If this does not happen, human communication tends to become oppressive of difference, introducing imbalances and disconnections that cause harm (such as food shortages, global warming, war).

A social system can only deal with the above imbalances and disconnections if they are recognised and legitimised as concerns that are derived from, and necessary to, its method of communication. University-community engagement therefore plays a vital role in maintaining the flow of communication between society and a universe of discourse that is independent of what we want to be the case.

\section{REFERENCES}

Australian Universities Community Engagement Alliance 2005, Funding Australian universities for community engagement, Australian Universities Community Engagement Alliance, Penrith, Queensland.

Commonwealth of Australia 2002, Higher education at the crossroads: An overview paper, Department of Education, Science and Training, Canberra.

Corrington, RS 1994, Ecstatic naturalism: Signs of the world, Indiana University Press, Bloomington.

Douglas, M 1973, Natural symbols: Explorations in cosmology, Penguin, London.

Douglas, M 1982a, In the active voice, Routledge \& Kegan Paul, London.

Douglas, M (ed.) 1982b, Essays in the sociology of perception, Routledge \& Kegan Paul, London.

Douglas, M 1989, 'The background of the grid dimension: A comment', Sociological Analysis, vol. 50, no. 2, pp. 171-176.

Douglas, M 2001, A feeling for hierarchy, unpublished manuscript, (draft 3 , November 1). 
Douglas, M \& Calvez, M 1990, 'The self as risk taker: A cultural theory of contagion in relation to AIDS', The Sociological Review, vol. 38, no. 3, pp. 445464.

Douglas, M \& Wildavsky, A 1982, Risk and culture: An essay on the selection of technical and environmental dangers, University of California Press, Berkeley.

Hawes, L 1999, 'The dialogics of conversation: Power, control, vulnerability', Communication Theory, vol. 9, no. 3, pp. 229-264.

Innovative Research Universities Australia 2006, Response to DEST knowledge transfer project, Innovative Research Universities Australia, Nathan, Queensland.

Kecskes, K 2006, 'Behind the rhetoric: Applying a cultural theory lens to community-campus partnership development', Michigan Journal of Community Service Learning, vol. 12, no. 2, pp. 5-14.

Kevelson, R 1993, Peirce's esthetics of freedom: Possibility, complexity, and emergent value, Peter Lang, New York.

Kurtz, C \& Snowden, D 2003, 'The new dynamics of strategy: Sense-making in a complex and complicated world', IBM Systems Journal, vol. 42, no. 3, pp. 462-483.

Latour, B 2000, 'When things strike back: A possible contribution of 'science studies' to the social sciences', British Journal of Sociology, vol. 51, no. 1, pp. $107-123$.

Low, D 2000, 'The nonviolent principles of scientific communication', Australian Journal of Communication, vol. 27, no. 3, pp. 39-48.

Low, D 2003, Environmental communication: Dissent, conflict, enquiry, PhD. Thesis, Australian National University, Canberra.

Luhmann, N 1989, Ecological communication, trans. J Bednarz Jr, University of Chicago Press, Chicago.

Luhmann, N (ed.) 1990, Essays on self-reference, Columbia University Press, New York.

Lyne, J 1982, 'C. S. Peirce's philosophy of rhetoric', in B Vickers (ed.),

Rhetoric revalued: Papers from the International Society for the History of Rhetoric, Center for Medieval and Early Renaissance Studies, New York.

Mamadouh, V 1999, 'Grid-group cultural theory: An introduction', Geojournal, vol. 47, no. 3, pp. 395-409

McGee, M \& Lyne, J 1987, ‘What are nice folks like you doing in a place like this? Some entailments of treating knowledge claims rhetorically', in JS Nelson, A Megill \& DN McClosky (eds), The rhetoric of the human sciences: 
Language and argument in scholarship and human affairs, University of Wisconsin Press, Madison, pp. 381-406.

Nicholls, A 2000, 'The secularization of revelation from Plato to Freud', Contretemps, vol 1, September, pp. 62-70.

Peirce, C 1955, in J Buchler (ed.), Philosophical writings of Peirce, Dover, New York.

Peirce, C 1976, in C Eisele (ed.), The new elements of mathematics, vol. 4, Mouton, The Hague.

Peirce, C 1998, in Peirce Edition Project (eds), The essential Peirce: Selected philosophical writings, vol. 2, Indiana University Press, Bloomington.

Perelman, C 1982, The realm of rhetoric, trans. W. Kluback, University of Notre Dame Press, Notre Dame.

6, P, Goodwin, N, Peck, E \& Freeman, T 2006, Managing networks of twentyfirst century organisations, Palgrave, New York.

Ransdell, J 1998, 'Sciences as communicational communities' (Ver 3.1, online). Viewed 2 February 2007, http: / / cspeirce.com/menu/library / aboutcsp/ ransdell/ physics.htm

Shellenberger, M \& Nordhaus, T 2005, 'The death of environmentalism', The Sun, no. 350, pp. 12-15.

Spickard, J 1989, 'A guide to Mary Douglas's three versions of grid/group theory', Sociological Analysis, vol. 50, no. 2, pp. 151-170.

Thompson, M 1992, 'The dynamics of cultural theory and their implications for the enterprise culture', in S Hargreaves Heap \& A Ross (eds),

Understanding the enterprise culture: Themes in the work of Mary Douglas, Edinburgh University Press, Edinburgh.

Thompson, M 2000, 'Global networks and local cultures: What are the mismatches and what can be done about them?' in C Engel \& KH Keller (eds), Understanding the impact of global networks on local, social, political and cultural values, Nomos, Baden-Baden.

Van Dijck, J 2003, 'After the 'two cultures': Toward a '(multi)cultural' practice of science communication', Science Communication, vol. 25, no. 2, pp. 177-190.

Winter, A, Wiseman, J \& Muirhead, B 2006, 'University-community engagement in Australia: Practice, policy and public good', Education, Citizenship and Social Justice, vol. 1, no. 3, pp. 211-230. 